\title{
316L metal powder compaction simulation with assisted friction
}

\author{
loana Monica SAS-BOCA ${ }^{1, a}$, Dan FRUNZA ${ }^{2, b}$ \\ and Dana-Adriana ILUTुIU-VARVARA ${ }^{2, c}$ \\ ${ }^{1}$ Technical University of Cluj - Napoca, Muncii Avenue 103-105, 400641 Cluj-Napoca, Romania \\ ${ }^{2}$ Technical University of Cluj - Napoca, Memorandumului Street 28, 400114, Cluj - Napoca, \\ Romania
}

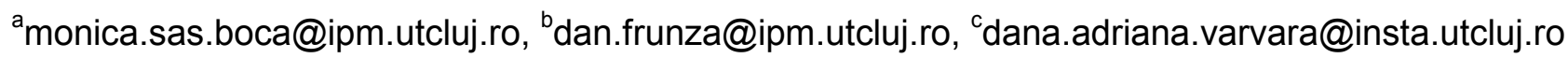

Keywords: conversion, simulation, metal powder, active friction forces.

\begin{abstract}
Friction plays a major role in powder compaction and there is a large energy loss in trying to overcome its negative effects. It is therefore rational to use the friction to assist metal flows and reducing the amount of lubricant and its negative effects. The appropriate use of friction in practice involves the solving of complex engineering problems. The paper approach will mainly focus upon issues concerning the conversion of the friction force and simulation in PM compaction processes and improving density gradient in the powder compaction process of AISI 316L austenitic powder.
\end{abstract}

\section{Introduction}

The development of bulk plastic deformation processes highly depends on the presence of friction. The friction phenomenon can have positive or negative consequences. The powder compaction process leads to both displacement among particles and displacement of particles with respect to the die wall.

In view of the great loss of energy involved in overcoming the friction [1], a rational approach to the problem is to use friction to help the flow of metal in these processes. Heterogeneity of the density distribution is a result of the stress transmission $[2,3,4]$ that depends on the internal friction, as well as boundary conditions, contact metal powder/tools and lubrication. The friction between metal powder and die during the compaction process leads to heterogeneity of the density distribution. This heterogeneity has effects on mechanical resistance of compacts $[5,6]$. The density variation $[5,7,8,9,10,11,12]$ in green compacts is subject to damaging during manipulations or low resistance, durability and exploitation of parts. Heterogeneity of the density distribution is principally owed to the friction imposed between tools and metal powder [5].

This issue has been tackled by other authors $[3,7,13]$ in the last 20 years, which shows an interest in optimizing the compaction process by converting friction forces at the contact the die/metal powder.

The main objective of this paper consists in improving density gradient in the powder compaction process, in defining a coherent approach platform for the present-day trends in powder metallurgy research and development a compaction process that could be used as a starting point for advanced powder processing technologies.

\section{Materials and experimental procedure}

Activation technique of friction forces at the contact die/metal powder is the same as described in previous works $[5,6,7]$ drive the mold in the same direction as the movement of the punch with higher speed. By moving the die to the punch direction according of a particularly speed, the friction force acts in the same sense as the pressing load with the results of improving pressing condition.

This activation of friction $[1,3]$, in PM compaction processes, create a peripheral flow which causes the material in the central and peripheral axial-flow direction. Material from these two regions can move simultaneously in the die resulting in reduction of strains and their uniformity, the 
increased strain and increase working speed and increase the degree of deformation. Thus, this procedure creates additional opportunities for reducing or eliminating the deformations due to flow uniformity and standardization of their right under certain conditions.

The paper presents simulation results of compaction with active friction forces and the density distribution maps (Fig. 1) for cylindrical parts $(5.5 \mathrm{~g})$ of AISI $316 \mathrm{~L}$ austenitic steel during the pressing process which satisfies the relation $\mathrm{h} / \mathrm{d}$ to be higher than one.

Cold compaction using activated friction force method was used. Lubricant used for this analysis was zinc stearate $\left(\mathrm{C}_{36} \mathrm{H}_{70} \mathrm{O}_{4} \mathrm{Zn}\right)$ while friction coefficient at metal powder/tool interface used was 0.1 .

The proposed process consists in moving the die throughout the pressing, die movement in the same direction [5,6]. As a result, the frictional forces acting in the same direction as the punch achieving a better distribution of metal powderflow during compaction process.

For simulation analyses using friction-assisted compaction technique was used nonlinear FEA software, MSC. Marc. The model is a 2-D axisymmetric model.

Powder yield criteria presented in the model incorporated into MSC. Marc, a unified viscoplastic approach is used to analyze metal powder material [14]. The yield function is:

$$
F=\frac{1}{\gamma} \sqrt{\frac{3}{2} \sigma^{2 d}+\frac{p^{2}}{\beta^{2}}}-\sigma_{y}
$$

where: $\sigma_{y}$ is the uniaxial yield stress $[\mathrm{MPa}], \sigma^{d}$ is the deviatoric stress tensor [MPa], $p$ is the hydrostatic pressure [MPa], and $\gamma, \beta$ are material parameters, functions only of relative density [14].

For this approach, the kinematics of rigid bodies (pressing tools: upper, lower punch or die) was prescribed using velocity option of MSC. Marc software. Before running of the finite element analysis, all rigid bodies were brought into contact with deformable body (metal powder).

For proper simulation analysis were introduced in the initial conditions, a total of 476 quadrilateral mesh elements and 531 numbers of nodes in mesh, tools velocity and initial height of the metal powder column, displacement and the variable time. Coefficient of thermal expansion was ignored, due to the compaction process was carried out at ambient temperature. Velocity tools were constant and velocity ratio is expressed by relation:

$$
\begin{aligned}
& V_{m}=1.5 \cdot V_{p}[\mathrm{~m} / \mathrm{s}] \\
& V_{m} \text { - velocity die }[\mathrm{m} / \mathrm{s}] \\
& V_{p}=0.6[\mathrm{~m} / \mathrm{s}] \text { - velocity lower punch }
\end{aligned}
$$

Powder material parameters and relative density $88 \%$ were entered in FEA software before running analysis.

\section{Results and discussions}

MSC. Marc software was used to simulate the compaction process of austenitic steel powder 316L. The wall friction effect was considered by adopting a Coulombic boundary condition on the interfaces powder/wall die and powder/punch [5]. In the model incorporated into software a unified viscoplastic approach is used. Compaction pressure introduced into the simulation (pressure of lower punch) was $800 \mathrm{MPa}$.

The friction coefficient is dependent on metal powder constitutive material [12] and of specific mixture powder materials - lubricant. Therefore, this is one of the limits MSC Marc software.

Evolution of density variation over the cross-sectional area of the compact is represented in following figure (Fig.1a,b,c). 


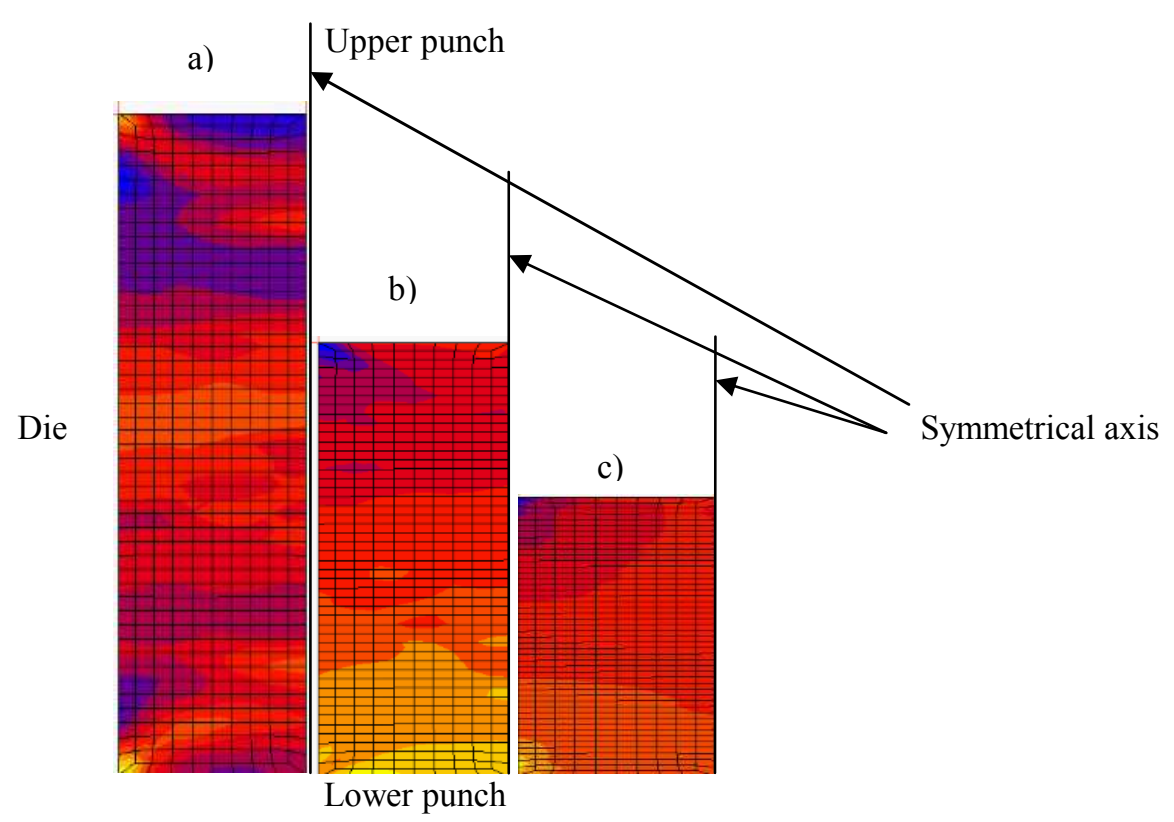

Fig. 1 Density distribution process of austenitic steel powder $316 \mathrm{~L}$

Was obtained by simulating an increase of relative density up to $89.54 \%$ for a ratio $\mathrm{Vm} / \mathrm{Vp}=$ 1.5 (light shade Fig. 1,c).

This gradient of density distribution throughout the compacts height is between $45.66 \%-45.68 \%$ (Fig. 1,a) particle rearrangement phase, start of compaction and $87.89 \%-89.54 \%$ (Fig. 1,c) in endstage of compaction. Therefore, the gradient of density distribution throughout the cross-sectional area of the compacts is reduced.

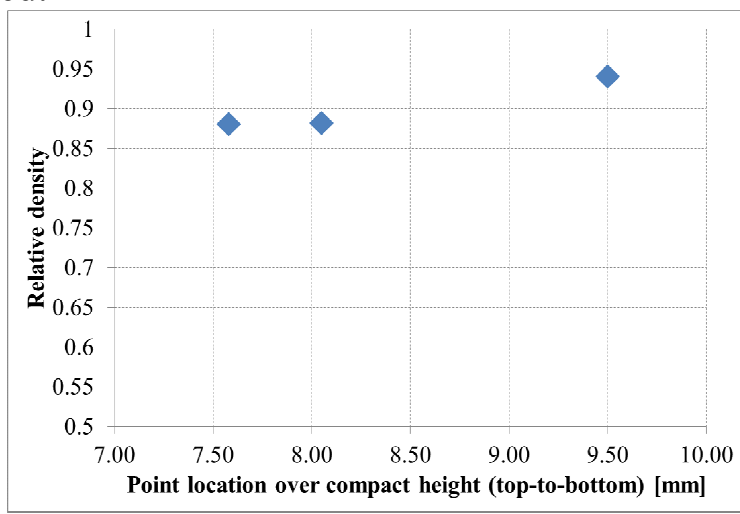

Fig. 2 Density distribution for compact

It can be seen that there is a similarity between the values obtained from finite element analysis (Fig. 1) and the experimental records (Fig. 2). Also, there is a discrepancy between the experimental results and the results obtained from finite analysis which may be attributed to the software limitations. Considering the minor differences mentioned above can be said that the purpose was achieved in the present work.

\section{Conclusions}

The simulation of the metal powder compaction process allowed reproducing the gradient of density. This method of compaction leads to an increase of homogeneity of the density on height of green compact.

More importantly, as a result of active friction forces, to a closer observation on the relative density values can observe an improvement of the density gradient. The difference between the highest and the lowest relative density values over the cross-sectional area of the compact is reduced. 
The main advantages of "assisted friction" include: controlling the distribution of deformation or decreasing its non-uniformity as necessary; increasing or decreasing the shear component of deformation.

Simulation results have demonstrated a more uniform distribution of density across the height of the compact obtained by activation of friction forces.

\section{References}

[1] V. L. Berezhnoy, Non-Traditional Process Techniques of Extrusion and Pressing, Int J Adv Manuf Technol (2000) 16:19-22 2000 Springer-Verlag London Limited.

[2] H. Diarra, V. Mazel, A. Boillon, L. Rehault, V. Busignies, S. Bureau, P. Tchoreloff, Finite Element Method (FEM) modeling of the powder compaction of cosmetic products: Comparison between simulated and experimental results, Powder Technology 224 (2012) 233-2402.

[3] O. Kostiv, K. Behdinan, S. Hashemi, Finite Element Analysis of Friction-Assisted Powder Compaction Process., (2012) SAE International Journal of Materials and Manufacturing, 5 (2), pp. 333-344.3.

[4] A.R. Khoei, Computational Plasticity in Powder Forming Processes, Elsevier Ltd., UK, , ISBN $0080446361,2005$.

[5] I.M. Sas-Boca, D. Frunza, HSS Metal Powder Compaction Simulation with Assisted Friction, Global Research Analysis Website: Volume: 2, Issue: 10, Oct 2013 ISSN No 2277 - 8160.

[6] S. Shima, Finite Element Simulation of Compaction, Int. J. Powder Metall. 38 (2), (2002), pp. 41-47, doi: 10.1088/1757-899X/10/1/012077.

[7] T. Canta, D. Frunza, Friction-assisted pressing of PM components, Conference: International Conference on Advanced Materials Processing Technologies, Madrid, Spain Sep 18-21, 2001 Journal of Materials Processing Technology (2003) Volume: 143 Special Issue: SI Pages: 645-650.

[8] I.M Sas-Boca, Research on the use of friction force as an active deformation force in compaction processes, $\mathrm{PhD}$ thesis, Technical University of Cluj-Napoca, November (2012).

[9] I.M Sas-Boca., D. Frunza, A study of simulation made on powder compaction using friction force as active force, Advanced Composite Materials Engineering - COMAT 2012, Lux Libris; (2012) ISBN 978-973-131-164-7.

[10]M. Sas-Boca, Experimental study regarding compressing process with friction force, Advanced Materials Research Vol. 23 (2007), p. 177-180, 2007 Trans Tech Publications, Switzerland, http://www.scientific.net/AMR.23.177.

[11]M. Oyane, S. Shima, T. Tabata, Consideration of Basic Equation s, and their Application, in the Forming of Metal Powders and Porous Metals, Journal of Mechanical Working Technology 1, (1978), 325-341.

[12] M. Oldenburg, H.-A. Häggblad, B. Wikman, A Friction Model for Iron Powder Pressing Based on a Tribological Approach, Advances in Powder Metallurgy and Particulate Materials, 7, (1996), 329-340.

[13]D.-G. Wang, Y.-C. Wu, M.-H. Jiao, X. Ting, J.-W Yu, Research of Favorable Conversion of Friction during Powder Compaction, Material Science Forum, 575-578(1), (2008), 443-448.

[14]MSC. Marc, Software Corporation, Volume A: Theory and User Information." U.S.A. Version 2005. 